\title{
Prevalence of Rhesus \& Kell phenotypes among blood donors of Bangladesh
}

\author{
Ayesha Khatun, Sheikh Saiful Islam Shaheen, Atiar Rahman, Subarna Saha, Sushanta Kumar Basak
}

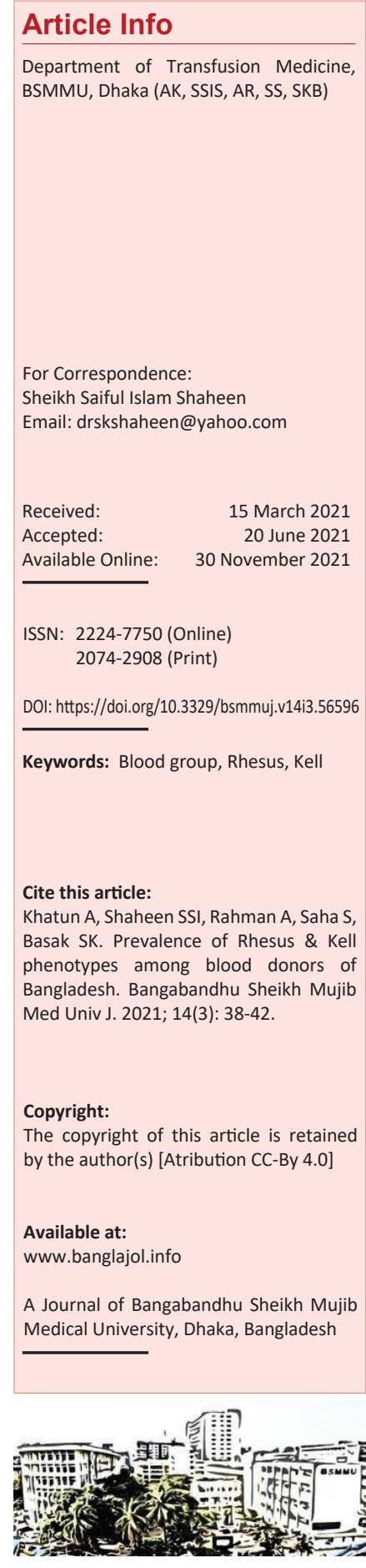

\begin{abstract}
The Rhesus blood group system is one of the most polymorphic and highly immunogenic systems in humans. Because of its high and strong immunogenicity $\mathrm{Rh} \mathrm{D}$ antigen testing is mandatory before issuing a compatible blood. There are five major antigens i.e. DCEce in the Rhesus ( $\mathrm{Rh}$ ) blood group system. On the other hand from the immunogenicity point of view Kell antigen is next to the $\mathrm{Rh}$ system. Both of them may cause severe hemolytic transfusion reaction and hemolytic disease of fetus and new born. Exposure of Rhesus negative individuals to Rhesus positive blood through transfusion or pregnancy is most likely to stimulate production of Rhesus antibodies. These antibodies may cause Hemolytic Disease of Fetus and Newborn (HDFN) and Delayed Hemolytic Transfusion Reaction (DHTR). Like Rhesus antibodies, Kell antibodies may also cause HDFN and DHTR. So far we know, there is not enough study regarding antigens C, c, E \& e of Rh or K, k antigen of Kell blood group system regarding these antigens in the donors in Bangladesh, thereby exposing transfused patients to these antigens negative patients. To determine the phenotype prevalence of the Rh and Kell blood group systems in the blood donors in Bangladesh, a descriptive cross sectional study was done in the laboratory of Department of Transfusion Medicine, Bangabandhu Sheikh Mujib Medical University, during the period of 1st January 2020 to 31 December 2020. Rhesus Phenotype CCDee is highest $(48.4 \%)$ \& CCDEe \& ccDEE both are lowest $(0.4 \%)$. Most probable Rhesus Genotype CDe/CDe (R1R1) is highest (48.4\%) and CDe/CDE (R1Rz) \& cDE/cDE (R2R2) both are lowest (0.4\%). Kell Genotype kk is highest $(99.2 \%)$ and $\mathrm{Kk}$ is lowest $(0.8 \%)$.
\end{abstract}

\section{Introduction}

Karl Landsteiner and Wiener discovered Rhesus (Rh) antigen in 1940, one of the most polymorphic and immunogenic systems is Rhesus (Rh) system. As it is highly immunogenic, testing for the RhD along with the $\mathrm{A}, \mathrm{B}$ antigens has been made mandatory in pre-transfusion testing.

There are more than 52 antigens in the $\mathrm{Rh}$ blood group discovered at present, but the major ones are D,C,E, c and e. In the Kell blood group system, more than 24 antigens have been discovered, among them Kell (K) and $\mathrm{k}$ (Cellano) is the most important.

There is not enough report available regarding the prevalence of these antigens in the people of Bangladesh.

The phenotype of a blood group of an individual is the observable expression of the genes inherited by the person and reflects the biologic activity of the genes. The presence or absence of antigens on red cells as determined by serological testing represents the phenotype. ${ }^{1}$

The phenotype of clinically significant blood group antigens on the donor red blood cells (RBC) is required to be known at times when alloimmunization is particularly undesirable, as in young females, pregnant women, and patients who are expected to require repeated transfusions in life, such as thalassemia or sickle cell disease patients. When selecting blood for transfusion to such patients, it would be useful if we have access to already phenotyped RBCs of donor population so that particular antigen typed blood can be given to such patients to prevent alloimmunization. ${ }^{2}$

In sub-saharan countries, few practice this systematic search for antigens C, c, e, E and K in the donors and recipients, thereby exposing the transfused patient to high risk of alloimmunization. ${ }^{3}$ 
The typing of blood group antigens and determination of phenotype for blood and blood components are a prerequisite for an efficient and safe blood transfusion. Rh antibodies are usually immunoglobulin G, and they are produced early during life. ${ }^{4-6}$

The knowledge of the distribution of Rhesus antigen in a population is critical in managing a transfusion service in areas such as antenatal serology, paternity testing as well as selecting compatible blood and blood products. Even after karl Landsteiner's discovery in 1990, transfusion reactions were still prevalent. ${ }^{7}$

Knowledge about the frequency of red cells antigens phenotypes in Ivorian population is important for the creation of a donor data bank and to minimize risks of alloimmunization. This requires the determination of the immunological characteristics of blood products and blood recipients by performing immunohematological analysis such as phenotyping in $\mathrm{Rh}$ and Kell blood group systems. Currently, there are thirty-three major blood group systems. ${ }^{8}$

Blood group prevalence plays a role in evolution, genetics research, blood transfusion and organ transplantation. Modern medicine is also working on relationship of blood group with environment. ${ }^{9}$

Study of Rhesus (Rh) blood group antigens, Phenotype and Rh antibodies are very useful in routine and advanced clinical practice in blood transfusion center. Moreover, it can be used for population genetic studies. ${ }^{10,11}$

Eight percent of $\mathrm{D}$ negative patients exposed to $\mathrm{D}$ positive red cells may develop anti-D IgG antibodies that may persist for the rest of their lives, which can cause Hemolytic Transfusion Reaction (HTR) and Disease of Fetus and Newborn (HDFN). ${ }^{12}$

\section{Methods}

A Descriptive cross-sectional study was conducted from $1^{\text {st }}$ January 2020 to $31^{\text {st }}$ December 2020 in the Department of Transfusion Medicine, BSMMU. A structured questionnaire was used.

Blood donors coming to the Department of Transfusion Medicine, BSMMU fulfilling inclusion criteria were taken as sample by purposive convenient sampling technique. Inclusion criteria were fulfilled for being a blood donor. The participants consented to participate voluntarily in the present study. The data obtained from this study was analyzed for frequencies (absolute) and percentage.

\section{Results}

The study comprised of 256 donors. Among the 256 donors, 21-30 years age group donor is more (53.9\%) and $41-50$ years age group donor is less $(7.4 \%)$. Male donor is predominant $(89.8 \%)$ and Female donor is $(10.2 \%)$. (Table-I, Table-II)

In case of $\mathrm{ABO} \& \mathrm{Rh}(\mathrm{D})$ blood groups donors, $\mathrm{O} \mathrm{Rh}(\mathrm{D})+\mathrm{ve}$ donor is more (33.2\%) \& O Rh(D)-ve donor is lowest $(0.8 \%)$. In this study, Rhesus Phenotype CCDee is highest $(48.4 \%)$ \& CCDEe \& ccDEE both are lowest $(0.4 \%)$. Most probable Rhesus Genotype CDe/CDe $\left(\mathrm{R}_{1} \mathrm{R}_{1}\right)$ is highest $(48.4 \%)$ and CDe/CDE $\left(\mathrm{R}_{1} \mathrm{R}_{\mathrm{z}}\right)$ \& $\mathrm{cDE} / \mathrm{cDE}\left(\mathrm{R}_{2} \mathrm{R}_{2}\right)$ both are lowest $(0.4 \%)$. In this study, Kell Genotype kk is highest (99.2\%) and $\mathrm{Kk}$ is lowest $(0.8 \%)$. Among 6 A-ve blood group donors, all Rh genotypes are cde/cde (rr) (100\%). Among $63 \mathrm{~A}+\mathrm{ve}$ blood group donors, most $\mathrm{Rh}$ genotypes are $\mathrm{CDe} / \mathrm{CDe}\left(\mathrm{R}_{1} \mathrm{R}_{1}\right)(52.4 \%)$ and lowest are $c D e / c D e\left(R_{0} R_{0}\right)(1.6 \%)$.Among $17 \mathrm{AB}+$ ve blood group donors, most $\mathrm{Rh}$ genotypes are $\mathrm{CDe} / \mathrm{CDe}\left(\mathrm{R}_{1} \mathrm{R}_{1}\right)(41.2 \%)$ and lowest are CDe/Cde $\left(R_{1} R_{2}\right)(11.8 \%)$.Among 10 B-ve blood group donors, most Rh genotypes are cde/cde (rr) $(80.0 \%)$ and lowest are Cde/cde (r'r) (20.0\%).Among $73 \mathrm{~B}+$ ve blood group donors, most $\mathrm{Rh}$ genotypes are $\mathrm{CDe} / \mathrm{CDe}\left(\mathrm{R}_{1} \mathrm{R}_{1}\right)(50.7 \%)$ and lowest are $c D e / c D e\left(R_{0} R_{0}\right)(1.4 \%) \& C D e / C D E\left(R_{1} R_{Z}\right)(1.4 \%)$. Among $02 \mathrm{O}$-ve blood group donors, all $\mathrm{Rh}$ genotypes are cde/cde (rr) (100\%).Among 85 O+ve blood group donors, most $\mathrm{Rh}$ genotypes are $\mathrm{CDe} / \mathrm{CDe}\left(\mathrm{R}_{1} \mathrm{R}_{1}\right)(55.3 \%)$ and lowest are $c D e / c D e\left(R_{0} R_{0}\right)(1.2 \%) \& c D E / c D E\left(R_{2} R_{2}\right)(1.2 \%)$. In this study, only 2 study samples are Kk genotype, 1 is $\mathrm{O}+$ ve blood group another is A+ve blood group. (Table-III)

\section{Table-I}

\section{Age distribution of the study respondents $(n=256)$}

\begin{tabular}{|l|c|c|}
\hline Age (years) & Frequency (n) & Percentage (\%) \\
\hline$<20$ & 19 & 7.4 \\
\hline $21-30$ & 138 & 53.9 \\
\hline $31-40$ & 80 & 31.3 \\
\hline $41-50$ & 19 & 7.4 \\
\hline Total & 256 & 100.0 \\
\hline $\begin{array}{l}\text { Mean } \pm \text { SD } \\
\text { Range (min - max) }\end{array}$ & \multicolumn{2}{|c|}{$18-50.6 .9$} \\
\hline
\end{tabular}

Table-II

Sex distribution of the study respondents $(n=256)$

\begin{tabular}{|l|c|c|}
\hline Sex & Frequency (n) & Percentage (\%) \\
\hline Male & 230 & 89.8 \\
\hline Female & 26 & 10.2 \\
\hline Total & 256 & 100.0 \\
\hline Male : Female & \multicolumn{2}{|c|}{$8.8: 1$} \\
\hline
\end{tabular}




\begin{tabular}{|l|c|c|}
\hline \multicolumn{3}{|c|}{ Table-III } \\
\hline \multicolumn{2}{|c|}{$\begin{array}{c}\text { Frequency of most probable Rhesus genotype in the } \\
\text { studied respondents }(\mathbf{n}=256)\end{array}$} \\
\hline Most Probable Rhesus genotype & Frequency $(\mathrm{n})$ & Percentage $(\%)$ \\
\hline Cde/cde $\left(\mathrm{r}^{\prime} \mathrm{r}\right)$ & 2 & 0.8 \\
\hline $\mathrm{cDe} / \mathrm{cDe}\left(\mathrm{R}_{0} \mathrm{R}_{0}\right)$ & 6 & 2.3 \\
\hline $\mathrm{CDe} / \mathrm{cde}\left(\mathrm{R}_{1} \mathrm{r}\right)$ & 68 & 26.6 \\
\hline $\mathrm{CDe} / \mathrm{CDe}\left(\mathrm{R}_{1} \mathrm{R}_{1}\right)$ & 124 & 48.4 \\
\hline $\mathrm{CDe} / \mathrm{cDE}\left(\mathrm{R}_{1} \mathrm{R}_{2}\right)$ & 26 & 10.2 \\
\hline $\mathrm{CDe} / \mathrm{CDE}\left(\mathrm{R}_{1} \mathrm{R}_{2}\right)$ & 1 & 0.4 \\
\hline $\mathrm{cDE} / \mathrm{cde}\left(\mathrm{R}_{2} \mathrm{r}\right)$ & 12 & 4.7 \\
\hline $\mathrm{cDE} / \mathrm{cDE}\left(\mathrm{R}_{2} \mathrm{R}_{2}\right)$ & 1 & 0.4 \\
\hline cde/cde $(\mathrm{rr})$ & 16 & 6.3 \\
\hline Total & 256 & 100.0 \\
\hline
\end{tabular}

Most probable Rhesus Genotype CDe/CDe (R1R1) is highest $(48.4 \%)$ and $\mathrm{CDe} / \mathrm{CDE}(\mathrm{R} 1 \mathrm{Rz})$ \& $\mathrm{cDE} / \mathrm{cDE}$ (R2R2) both are lowest $(0.4 \%)$. (Table-IV)
Table-V

\begin{tabular}{|c|c|c|}
\hline \multicolumn{3}{|c|}{$\begin{array}{l}\text { Frequency of Kell genotype in the studied respondents } \\
\qquad(\mathrm{n}=256)\end{array}$} \\
\hline Kell genotype & Frequency (n) & Percentage (\%) \\
\hline kk & 254 & 99.2 \\
\hline $\mathrm{Kk}$ & 2 & 0.8 \\
\hline Total & 256 & 100.0 \\
\hline
\end{tabular}

In this study, Kell Genotype kk is highest (99.2\%) and $\mathrm{Kk}$ is lowest $(0.8 \%)$. (Table-V)

Among 6 A-ve blood group donors, all Rh genotypes are cde/cde (rr) (100\%). Among $63 \mathrm{~A}+\mathrm{ve}$ blood group donors, most $\mathrm{Rh}$ genotypes are $\mathrm{CDe} / \mathrm{CDe}\left(\mathrm{R}_{1} \mathrm{R}_{1}\right)(52.4 \%)$ and lowest are $c D e / c D e\left(R_{0} R_{0}\right)(1.6 \%)$.Among $17 \mathrm{AB}+$ ve blood group donors, most $\mathrm{Rh}$ genotypes are $\mathrm{CDe} / \mathrm{CDe}\left(\mathrm{R}_{1} \mathrm{R}_{1}\right)(41.2 \%)$ and lowest are $\mathrm{CDe} / \mathrm{Cde}\left(\mathrm{R}_{1} \mathrm{R}_{2}\right)(11.8 \%)$. Among $10 \mathrm{~B}$-ve blood group donors, most Rh genotypes are cde/cde (rr) (80.0\%) and lowest are Cde/cde (r'r) (20.0\%).Among $73 \mathrm{~B}+$ ve blood group donors, most $\mathrm{Rh}$ genotypes are $\mathrm{CDe} / \mathrm{CDe}\left(\mathrm{R}_{1} \mathrm{R}_{1}\right)(50.7 \%)$ and lowest are cDe/cDe $\left(\mathrm{R}_{0} \mathrm{R}_{0}\right)(1.4 \%) \quad \& \quad \mathrm{CDe} / \mathrm{CDE}$ $\left(\mathrm{R}_{1} \mathrm{R}_{\mathrm{Z}}\right)(1.4 \%)$.Among $02 \mathrm{O}$-ve blood group donors, all $\mathrm{Rh}$ genotypes are cde/cde (rr) (100\%). Among 85 O+ve blood group donors, most $\mathrm{Rh}$ genotypes are $\mathrm{CDe} / \mathrm{CDe}\left(\mathrm{R}_{1} \mathrm{R}_{1}\right)(55.3 \%)$ and lowest are cDe/cDe $\left(\mathrm{R}_{0} \mathrm{R}_{0}\right)(1.2 \%)$ \& $\mathrm{cDE} / \mathrm{cDE}\left(\mathrm{R}_{2} \mathrm{R}_{2}\right)$ $(1.2 \%)$. (Table-VI)

Table-IV

Most Probable Rhesus Genotype according to ABO \& Rh(D) blood group

\begin{tabular}{|c|c|c|c|c|c|c|c|c|}
\hline \multirow{2}{*}{$\begin{array}{l}\text { Most Probable } \\
\text { Rhesus Genotype }\end{array}$} & \multicolumn{7}{|c|}{ ABO \& Rh(D) Blood Group } & \multirow{2}{*}{$\begin{array}{c}\text { Total } \\
(n=256)\end{array}$} \\
\hline & $\begin{array}{l}\text { A-ve } \\
(n=6)\end{array}$ & $\begin{array}{l}\text { A+ve } \\
(n=63)\end{array}$ & $\begin{array}{c}A B+v e \\
(n=17)\end{array}$ & $\begin{array}{c}\text { B-ve } \\
(n=10)\end{array}$ & $\begin{array}{c}\text { B+ve } \\
(n=73)\end{array}$ & $\begin{array}{l}\text { O-ve } \\
(n=2)\end{array}$ & $\begin{array}{l}\text { O+ve } \\
(n=85)\end{array}$ & \\
\hline Cde/cde (r'r) & $0(0.0)$ & $0(0.0)$ & $0(0.0)$ & $2(20.0)$ & $0(0.0)$ & $0(0.0)$ & $0(0.0)$ & $2(0.8)$ \\
\hline $\mathrm{cDe} / \mathrm{cDe}\left(\mathrm{R}_{0} \mathrm{R}_{0}\right)$ & $0(0.0)$ & $1(1.6)$ & $3(17.6)$ & $0(0.0)$ & $1(1.4)$ & $0(0.0)$ & $1(1.2)$ & $6(2.3)$ \\
\hline CDe/cde $\left(R_{1} r\right)$ & $0(0.0)$ & $18(28.6)$ & $5(29.4)$ & $0(0.0)$ & $24(32.9)$ & $0(0.0)$ & $20(23.5)$ & $68(26.6)$ \\
\hline CDe/CDe $\left(R_{1} R_{1}\right)$ & $0(0.0)$ & $34(54.0)$ & $7(41.2)$ & $0(0.0)$ & $37(50.7)$ & $0(0.0)$ & $47(55.3)$ & $124(48.4)$ \\
\hline $\mathrm{CDe} / \mathrm{cDE}\left(\mathrm{R}_{1} \mathrm{R}_{2}\right)$ & $0(0.0)$ & $7(11.1)$ & $2(11.8)$ & $0(0.0)$ & $5(6.8)$ & $0(0.0)$ & $12(14.1)$ & $26(10.2)$ \\
\hline $\operatorname{CDe} / \operatorname{CDE}\left(\mathbf{R}_{1} \mathbf{R}_{\mathrm{Z}}\right)$ & $0(0.0)$ & $0(0.0)$ & $0(0.0)$ & $0(0.0)$ & $1(1.4)$ & $0(0.0)$ & $0(0.0)$ & $1(0.4)$ \\
\hline cDE/cde $\left(\mathbf{R}_{\mathbf{2}} \mathbf{r}\right)$ & $0(0.0)$ & $3(4.8)$ & $0(0.0)$ & $0(0.0)$ & $5(6.8)$ & $0(0.0)$ & $4(4.7)$ & $12(4.7)$ \\
\hline $\operatorname{cDE} / \mathrm{cDE}\left(\mathbf{R}_{2} \mathbf{R}_{2}\right)$ & $0(0.0)$ & $0(0.0)$ & $0(0.0)$ & $0(0.0)$ & $0(0.0)$ & $0(0.0)$ & $1(1.2)$ & $1(0.4)$ \\
\hline cde/cde (rr) & $6(100.0)$ & $0(0.0)$ & $0(0.0)$ & $8(80.0)$ & $0(0.0)$ & $2(100.0)$ & $0(0.0)$ & $16(6.3)$ \\
\hline Total & $6(100)$ & $63(100)$ & $17(100)$ & $10(100)$ & $73(100)$ & $2(100)$ & $85(100)$ & $256(100)$ \\
\hline
\end{tabular}


Table-VI

\begin{tabular}{|c|c|c|c|c|c|c|c|c|}
\hline \multirow[t]{2}{*}{ Kell } & \multicolumn{7}{|c|}{$A B O \& R h(D)$ Blood Group } & \multirow{2}{*}{$\begin{array}{c}\text { Total } \\
(\mathrm{n}=256)\end{array}$} \\
\hline & $\begin{array}{l}\text { A-ve } \\
(n=6)\end{array}$ & $\begin{array}{l}\text { A+ve } \\
(n=63)\end{array}$ & $\begin{array}{l}\mathrm{AB}+\mathrm{ve} \\
(\mathrm{n}=17)\end{array}$ & $\begin{array}{c}\text { B-ve } \\
(\mathrm{n}=10)\end{array}$ & $\begin{array}{c}\text { B+ve } \\
(n=73)\end{array}$ & $\begin{array}{l}\text { O-ve } \\
(n=2)\end{array}$ & $\begin{array}{l}\text { O+ve } \\
(n=85)\end{array}$ & \\
\hline \multicolumn{9}{|c|}{ Genotype } \\
\hline $\mathrm{kk}$ & $6(100.0)$ & $62(98.4)$ & $17(100.0)$ & $10(100.0)$ & $73(100.0)$ & $2(100.0)$ & $84(98.8)$ & 254(99.2) \\
\hline $\mathrm{Kk}$ & $0(0.0)$ & $1(1.6)$ & $0(0.0)$ & $0(0.0)$ & $0(0.0)$ & $0(0.0)$ & $1(1.2)$ & $2(0.8)$ \\
\hline Total & $6(100.0)$ & $63(100.0)$ & 17(100.0) & $10(100.0)$ & $73(100.0)$ & $2(100.0)$ & $85(100.0)$ & $256(100.0)$ \\
\hline
\end{tabular}

In this study, only 2 study samples are Kk genotype, 1 is $\mathrm{O}+\mathrm{ve}$ blood group another is $\mathrm{A}+\mathrm{ve}$ blood group

\section{Discussion}

Among the 256 donors, 21-30 years age group donor is more $(53.9 \%)$ and $41-50$ years age group donor is less (7.4\%). Male donor is predominant $(89.8 \%)$ and Female donor is $(10.2 \%)$.In case of $\mathrm{ABO} \& \mathrm{Rh}(\mathrm{D})$ blood groups donors, $\mathrm{O} \mathrm{Rh}(\mathrm{D})+$ ve donor is more $(33.2 \%) \& \mathrm{O} R(\mathrm{D})$-ve donor is lowest $(0.8 \%)$. In this study, Rhesus Phenotype CCDee is highest $(48.4 \%)$ \& CCDEe $\&$ ccDEE both are lowest $(0.4 \%)$. Most probable Rhesus Genotype CDe/CDe $\left(\mathrm{R}_{1} \mathrm{R}_{1}\right)$ is highest $(48.4 \%)$ and $\mathrm{CDe} / \mathrm{CDE}$ $\left(R_{1} R_{z}\right)$ \& cDE/cDE $\left(R_{2} R_{2}\right)$ both are lowest $(0.4 \%)$.Similar results were found in the study of Sangeeta P,Sonal J et al where CCDee frequency was $42.2 \%$ and probable genotype was $R_{1} R_{1}(C D e / C D e) .{ }^{13}$ Some other studies also agreed with this study. ${ }^{14,15,16}$

In this study, Kell Genotype kk is highest (99.2\%) and $\mathrm{Kk}$ is lowest $(0.8 \%)$. A study in North Indian blood donors and some other studies agreed with this study. 13,17,18,19

Among 6 A-ve blood group donors, all Rh genotypes are cde/cde (rr) (100\%).Among $63 \mathrm{~A}+\mathrm{ve}$ blood group donors, most Rh genotypes are CDe/CDe $\left(R_{1} R_{1}\right)(52.4 \%)$ and lowest are $c D e / c D e\left(R_{0} R_{0}\right)(1.6 \%)$.Among $17 \mathrm{AB}+$ ve blood group donors, most $\mathrm{Rh}$ genotypes are $\mathrm{CDe} / \mathrm{CDe}\left(\mathrm{R}_{1} \mathrm{R}_{1}\right)(41.2 \%)$ and lowest are $\mathrm{CDe} / \mathrm{Cde}\left(\mathrm{R}_{1} \mathrm{R}_{2}\right)(11.8 \%)$.Among $10 \mathrm{~B}$-ve blood group donors, most Rh genotypes are cde/cde (rr) (80.0\%) and lowest are Cde/cde ( $\left.\mathrm{r}^{\prime} \mathrm{r}\right)(20.0 \%)$.Among $73 \mathrm{~B}+$ ve blood group donors, most $\mathrm{Rh}$ genotypes are $\mathrm{CDe} / \mathrm{CDe}\left(\mathrm{R}_{1} \mathrm{R}_{1}\right)(50.7 \%)$ and lowest are $c D e / c D e\left(R_{0} R_{0}\right)(1.4 \%) \& C D e / C D E\left(R_{1} R_{Z}\right)(1.4 \%)$. Among $02 \mathrm{O}$-ve blood group donors, all $\mathrm{Rh}$ genotypes are cde/cde (rr) (100\%).Among 85 O+ve blood group donors, most Rh genotypes are CDe/CDe $\left(R_{1} R_{1}\right)(55.3 \%)$ and lowest are $c D e / c D e\left(R_{0} R_{0}\right)(1.2 \%) \& c D E / c D E\left(R_{2} R_{2}\right)(1.2 \%)$. In this study, only 2 study samples are Kk genotype, 1 is $\mathrm{O}+$ ve blood group another is A+ve blood group.These findings were in accordance with the findings of previous studies by Hafid Z,Anass Y,Jean U et al. ${ }^{20}$

\section{Conclusion}

In case of Rhesus blood group system, most probable Rhesus Genotype $\mathrm{CDe} / \mathrm{CDe}\left(\mathrm{R}_{1} \mathrm{R}_{1}\right)$ is highest (48.4\%). These population are vulnerable to develop alloantibody against other red cell antigen. These alloantibody are clinically significant and can cause hemolytic disease of fetus and newborn \& hemolytic transfusion reaction. In case of Kell blood group system, Kell Genotype kk (Cellano) is highest $(99.2 \%)$ and $\mathrm{Kk}$ (Kell) is lowest $(0.8 \%)$. Kell antigen is very strong but frequency is low. In this case, alloimmunization causes severe hemolytic disease of fetus and newborn \& hemolytic transfusion reaction. It is very difficult to identify the cause. This study will help to make a donor pool and supply blood according to Rh phenotype \& Kell phenotype.

\section{Ethical issues}

This research was approved by the Institutional Review Board (IRB) of BSMMU. The participants were informed about the risks, benefits and possible outcomes of this work and the information were given in an easy and local language (Bengali). Informed written consent was taken from each donor.

\section{Conflict of Interest}

Authors declare no conflict of interest.

\section{Acknowledgement}

This research project was supported by a grant from University Grant Commission through Bangabandhu Sheikh Mujib Medical University, Dhaka. 


\section{References}

1. Kulkarni SS. Genetics of Rh Blood group system In: Snehalatha Gupte, Desai PK editors, Recent trends in Transfusion Medicine. SuratRaktadam Kendra and research center 2002; pp 98

2. Diedrich B, Andersson J, Sallander S, Shanwell A. Kell \& Duffy phenotyping of blood RBCs on microplates. PubMed 2001;41(10):1263-7.

3. Aker DP, Seka-Seka J, Dasse SR. Alloimmunisation anti erythrocytaire post transfusionnelle chez les drepanocytaires au CHU de Cocody Abidjan. International Journal of Pharma and Bio Sciences. 2008;(2):64-70.

4. Boturao-Neto E, Yamamoto M, Chiba AK, Kimura EY, de Oliveira MC, do Monte Barretto CL et al. Molecular basis of KEL null phenotype in Brazilians. Transfus Med Hemother. 2015;42:52-58.

5. Huang HJ, Tagawa H. Hemolytic disease of the newborn due to anti-Ku. Nippon Sanka Fujinka Gakkai Zasshi. 1982;34:119-21.

6. Fourmaintraux A, Vitrac D, Mariette JB, Brunel F. The K phenotype and fetal-maternal alloimmunization. Arch Fr Pediatr. 1993;50:779-781.

7. Lefrere J, Berche P. Landsteiner discovers the blood groups. TransfusClinBiol. 2010;17(1):1-8.

8. Sabtovito A, Burgarello C, Cervella P, et al. Erythrocyte polymorphisms in five ethnic groups of Northern Cote d'Ivoire. International Journal of Immunogenetics. 2009; 36(3):189-91.

9. Anees M, Jawad A, Hashmi I. Distribution of ABO and Rh blood group alleles in MandiBahauddin district of Punjab, Pakistan. Proc Pakistan Acad Sci. 2007;44(4):289-94.

10. Lee S, Russo D, Redman C. The kell blood group system: Kell and XK membrane proteins. Semin Hematol. 2000; 37:113-121.
11. Westhoff CM, Reid ME. Review: the Kell, Duffy, and Kidd blood group systems. Immunohematology. 2004; 20(1) : 37-49.

12. Wesrhoff CM, Siegel DL. Rossi's Principles of Transfusion Medicine. $4^{\text {th }}$ ed. Oxford: Wiley Blackwell aabb press; 2009. Rh and LW Blood Group Antigns In: Simon TM, Synder EL editors; pp. 109-20.

13. Sangeeta P, Sonal J, Manupriya. Assessment of rhesus and kell blood group antigens,phenotypes and their allelic frequencies in North Indian blood donors. Asian journal of Transfusion Science. 2020;14(2):137-41.

14. Musa RH, Ahimed SA, Hashim H, Ayob Y, Asidin NH, Choo py et al. Red cell phenotyping of blood from donors at the National Blood Center of Malaysia. Asian J Transfus Sci. 2012;6:3-9

15. Makroo R. Gupta R, Bhatia A, Rosamma NL. Rh phenotype, allele and haplotype frequencies among 51,857 Blood Donors in North India. Blood Transfus. 2013; 3:1-4

16. Danlels GL. Human Blood Groups. $2^{\text {nd }}$ ed. Oxford, United Kingdom; Blaxkwell Science; 2002 : pp 332-34

17. Pahuja S, Pujani M, Guota SK, Chandra J, Jain M. Alloimmunization and red cell autoimmunization in multitransfused thalassemics of Indian origin. Hematology. 2010;15:174-7.

18. Singer ST, Wu V, Mignacca R, Kuypers FA, Morel P, Vichinsky EP. Alloimmunization and erythrocyte autoimmunization in transfusion-dependent thalassemia patients of predominantly Asian descent. Blood. 2000;96:3369-73.

19. Ansari S, Voosogh P, Moshtaghian S. Assessment of frequency of alloimmunization and erythrocyte autoimmunization in transfusion dependent thalassemia patients. Acta Med Iran. 2008;46:137-40.

20. Hafid Z, Anass Y, Jean Uet. Phenotype frequencies of Rh and kell blood group systems in blood transfusion department of Avicenna Military hospital, Marrakech, Morocco. International journal of medicine \& health research. 2016;2(1):1-10. 